Núm. 26, 2022, pp. 129-151

https://doi.org/10.14198/AMESN.2022.26.08

Citación bibliográfica: Boccuti, Anna. "Espero que lo entienda: un ser así trae el futuro". Monstruosidad y género en los cuentos de Mónica Ojeda y Solange Rodríguez Pappe». América sin Nombre, 26 (2022): pp. 129-151. https://doi.org/10.14198/AMESN.2022.26.08

\title{
«Espero que lo entienda: un ser así trae el futuro». Monstruosidad y género en los cuentos de Mónica Ojeda y Solange Rodríguez Pappe
}

\section{«Espero que lo entienda: un ser así trae el futuro». Monstrosity and gender in the short stories of Mónica Ojeda and Solange Rodríguez Pappe}

\author{
AnNA Boccuti \\ Università degli Studi di Torino, Italia \\ anna.boccuti@unito.it \\ https://orcid.org/0000-0001-5079-8397
}

Fecha de recepción: 15/03/2021

Fecha de aceptación: 12/04/2021

\section{Resumen}

Este trabajo explora el retorno de los monstruos locales en la narrativa de Mónica Ojeda y Solange Rodríguez Pappe. En particular, nos detendremos en el uso del imaginario vinculado a figuras monstruosas de gran difusión en el mundo andino como las voladoras o las umas, que se revelan centrales en el proceso del empoderamiento de las protagonistas que estas autoras plantean en sus textos. A diferencia de otros cuentos fantásticos del siglo Xx donde el pasado prehispánico o «lo autóctono» aparece en clave monstruosa y por lo tanto ominosa, fijado como alteridad radical, en estas autoras -y en particular en algunos cuentos de Las voladoras (2020) de Ojeda y La primera vez que vi un fantasma (2018) de Rodríguez Pappe- los monstruos femeninos del folclore amerindio determinan reconocimientos sorprendentes y metamorfosis inesperadas, lo cual implica, como veremos, la reivindicación del poder abyecto de la monstruosidad: de esta manera, no sólo se subvierte la connotación 
del monstruo, sino que también se cuestionan y reescriben, desde el género, los arquetipos literarios que naturalizan el orden patriarcal de la cultura.

Palabras clave: género; bruja; monstruosidad femenina; mito; folclore; Mónica Ojeda; Solange Rodríguez Pappe.

\begin{abstract}
This paper explores the return of local monsters in the narrative of Mónica Ojeda and Solange Rodríguez Pappe. In particular, it focuses on the use of the imaginary linked to monstrous figures of great diffusion in the Andean world such as the voladoras or the umas, which prove to be key figures in the process of empowerment of the female protagonists that these writers represent in their texts. Unlike other fantastic short tales of the twentieth century where the pre-Hispanic past or «the autochthonous» appears in a monstrous and therefore ominous way, fixed as radical alterity, in these authors - and in particular in some short stories of Ojeda's Las voladoras (2020) and Rodríguez Pappe's La primera vez que vi un fantasma (2018) - the female monsters of Amerindian folklore determine surprising recognitions and unexpected metamorphoses, which implie, as we shall see, the vindication of the abject power of monstrosity: in this way, not only the connotation of the monster is subverted, but also the literary archetypes that naturalize the patriarchal order of culture are questioned and rewritten from the gender.
\end{abstract}

Keywords: gender; witch; monstrous-feminine; myth; folklore; Mónica Ojeda; Solange Rodríguez Pappe.

\title{
América, tierra de conquistadores y monstruos
}

América Latina ha sido tierra de monstruos y maravillas desde su primera «materialización» ante los ojos de los europeos: la alteridad y el exceso radicales que el continente viene a encarnar para los exploradores y los conquistadores llegados del otro lado del Atlántico representan un desafío epistémico excepcional, que exige un replanteamiento de todos los conocimientos de la época a través de categorías que exceden lo ordinario. Por ello, se recurre a los monstruos míticos de la tradición clásica y medieval, esos «monstruos geográficos» que forman parte de «una 'rejilla simbólica' que permite aprehender el espacio geográfico, da un sentido al mundo»(Rojas Mix 40). Tales monstruos «no aceptan aparecer como imaginarios, sino que son 'seres extraordinarios' en un mundo natural» (42), como señala Miguel Rojas Mix, autor de América Imaginaria, documentadísimo volumen sobre la representación de América Latina desde el 'Descubrimiento' hasta nuestros días. Efectivamente, un denso imaginario de monstruos y otras criaturas extraordinarias se despliega en las páginas de las crónicas americanas de los siglos XV y XVI, donde se narra de hombres «de color azul y cabeza cuadrada» (Rojas Mix, 5), con enormes orejas o un ojo solo, pero también se refieren encuentros con amazonas, sirenas, 
hombres lobo, gigantes... ${ }^{1}$ Cuando no son retratados como criaturas físicamente aberrantes, los nativos son monstruosos en el plano del ethos y la moral, su anomalía se exhibe así en el comportamiento y las normas de convivencia. La cuarta epístola atribuida a Americo Vespucci, Mondus Novus (1502), da constancia de este proceso: «Toman tantas mujeres cuantas quieren, y el hijo se mezcla con la madre, y el hermano con la hermana, y el primero con la primera, y el viandante con cualquiera que se encuentra. Cada vez que quieren deshacen el matrimonio y en esto ninguno observa orden» (ctd. en Giallongo 24).

Visto a través de la mirada colonizadora y la óptica eurocéntrica, el mundo americano y quienes lo habitan aparecen como lo que condensa la diferencia y todas las amenazas que ésta encierra. En el siglo XVII, como recuerda Mabel Moraña, este proceso de «monstrificación» de lo indígena no cesa, mas involucra otros variados ámbitos:

Dentro de la amplia caracterización de lo monstruoso, la sociedad colonial elabora una amplia gama de nociones vinculadas a lo demoníaco, desde el inofensivo curanderismo hasta la brujería, pasando por el peligro de los hechiceros, herbateros y chamanes, donde el desvío de las conductas doctrinarias del cristianismo configuraba un ámbito de anomalía que se vinculaba a lo oculto como espacio propio de razas consideradas inferiores y de sus imaginarios «irracionales». Rituales, creencias religiosas, supersticiones, leyendas $\mathrm{y}$ costumbres de origen amerindio o africano [...] eran monstrificados, perseguidos y castigados como sacrilegio (66-67, subrayado de la autora).

Lo que nos interesa destacar, al hilo de lo que ya han afirmado Rojas Mix y Morańa, es esta temprana inscripción de lo monstruoso en los saberes de los nativos americanos, connotados desde el principio como bárbaros e irreductibles al mundo civilizado europeo. La teratología y la mitología convergen aquí y se utilizan en clave política. En este sentido, en el continente americano se activa prematuramente el proceso de construcción social del monstruo, propio de la época moderna, con el fin de establecer una estrategia de dominación política y control social.

La connotación monstruosa se extiende inevitablemente también a todos aquellos elementos de la cultura precolombina y en particular del mito prehispánico, cuyas sanguinarias divinidades - desde Huitzilopochtli hasta Coyolchauqui o Coatlicue, para limitarnos al ámbito azteca- a veces se superponen a los monstruos del mito occidental ${ }^{2}$. Es a consecuencia de esta monstruosidad que el mundo prehispánico entra en la literatura que nos ocupa, lo fantástico hispanoamericano del siglo xx, cuyas manifestaciones están estrechamente ligadas al género que suele

1. Sobre la proyección de lo monstruoso en la representación de los pueblos originarios y de América, véase también Persephone Braham.

2. $\mathrm{Al}$ respecto, resultan evocadoras las reflexiones de Giallongo sobre las conexiones existentes en la iconografía de Coatlicue, Medusa y Eva, las tres representadas como «mujeres serpientes» (Giallongo 26). 
acoger a los monstruos y reelaborar las ansiedades, los miedos, las contradicciones de cada época: el gótico. Según Ana María Morales, quien se ha dedicado al análisis de un corpus de textos ya canónicos del género, como "Chac Mool» (Los días enmascarados, 1954) de Carlos Fuentes, «Axolotl» y «La noche boca arriba» (Final del juego, 1956), de Julio Cortázar, y «La fiesta brava» (El principio del placer, 1972), de José Emilio Pacheco, en estos cuentos el retorno a la vitalidad de las antiguas divinidades prehispánicas no sólo actúa como generador de la transgresión fantástica, sino que conlleva la irrupción en el presente de un pasado ominoso e irrecuperable, cuya aparición 'fantasmal' sugiere la reactivación de tensiones identitarias irresueltas. Morales insiste precisamente en el potencial perturbador acarreado por el retorno de un pasado objeto de remoción: «en esa colonización plena de creencias, lo prehispánico, lo mítico prehispánico, surge como una peligrosa alteridad que merma el mundo, devora las certezas, y puede desestabilizar incluso la propia identidad de los pueblos.» (Morales 74).

La relación entre el mito prehispánico, el terror y la monstruosidad es también objeto de las reflexiones de Karen Alejandra Calvo-Díaz, quien, a través de la lectura de un corpus de relatos mexicanos de los siglos XX-XXI, identifica lo que llama el "gótico mítico amerindio prehispánico» («Demonios latinos»). Según la académica, en cuentos como "La Llorona» (1936) de Artemio de Valle-Arispe, o en "Año cero» (2010) de Bernardo Esquinca, o en «La noche de Coatlicue» (2013) de Mauricio Molina, se utilizaría el mito prehispánico en clave terrorífica en primer lugar por su valor estético: de hecho, este pasado sigue encarnando la alteridad por excelencia, y como tal se presta a representar la monstruosidad en términos literarios (Calvo-Díaz, "Ciudad, terror y mito»). Quedarían por lo tanto en segundo plano otros sentidos y otras finalidades vinculados con la evocación del mundo prehispánico, es decir las construcciones utópicas o las reivindicaciones identitarias. Según Calvo-Díaz, en el "gótico mítico amerindio prehispánico» se daría una sustitución de los monstruos del gótico tradicional por las criaturas y los monstruos del imaginario autóctono ${ }^{3}$.

3. Entendemos el gótico como lo conceptualizó David Punter, es decir, como una tendencia que persiste en la literatura y las artes, caracterizada por la presencia recurrente de tropos y motivos a través de los cuales se cumple, de manera indirecta, el retorno de lo que ha sido reprimido, la emersión del lado oculto de la cultura, como subrayó Rosemary Jackson. La migración del gótico a América Latina es un objeto teórico de constitución relativamente reciente sobre el que, sin embargo, se han multiplicado rápidamente los estudios: entre los textos de referencia recordamos el de Edwards y Guardini Vasconcelos (2016), que plantea la existencia de un «gótico tropical» y el de Casanova-Vizcaíno y Ordiz (2018), que teoriza en cambio el "gótico latinoamericano». Dentro del gótico latinoamericano también se han identificado manifestaciones específicas, vinculadas con el contexto de referencia, como el «gótico andino» o el "gótico rioplatense» (que a su vez tendría otra articulación, o sea el "gótico federal, como reinvención del género 'situado' en las diversas regiones literarias argentinas», Nallim 80). Come recuerdan Edwards y Guardini Vasconcelos, en todas estas migraciones del modo gótico al Sur del 
Estos serían incluso más aterradores que los monstruos góticos precisamente a raíz de los significados subterráneos e inagotables que el mito, en tanto fragua de «relatos modélicos del imaginario colectivo», sigue emanando (Calvo-Díaz, "Demonios latinos» 350). El mito amerindio conocería así una sustancial transformación interpretativa en el contexto latinoamericano, pasando de la satanización de la época colonial a la exaltación de su potencial estético en las décadas más recientes, cuando los componentes puramente identitarios se diluirían en función de ese movimiento oscilante entre local y global propio de la época posmoderna ${ }^{4}$.

En una dirección similar van las consideraciones de Gabriele Bizzarri, quien, en realidad, no ciñe su reflexión específicamente a las manifestaciones del pasado mítico prehispánico, más bien a la continuación de este pasado en el repertorio mágico-folclórico, es decir «al regreso ominoso del elemento localista y ancestral (mito indígena, creencia de provincia etc.)» (210) «silenciado y espectralizado» (209). El ámbito de lo autóctono que aquí se indaga es inevitablemente mucho más amplio que el de "gótico amerindio» propuesto por Calvo-Díaz, e incluye múltiples y más genéricas declinaciones de «lo local», como pretendemos hacer en nuestro trabajo. Tampoco en el estudio de Bizzarri se vincula el elemento autóctono monstruoso con las reivindicaciones identitarias, puesto que, según el autor, las identidades marginales y menores que se materializan en lo fantástico ultra-contemporáneo serían fagocitadas por la corriente global, viendo neutralizada su pertenencia local. De esta manera, explica Bizzarri, estas identidades llegarían «a ser hebras de la misma urdimbre, o mejor, ininfluyentes grietas intersticiales necesarias para la eficacia de un discurso tan abierto y tolerante (pero en realidad tan voraz) de acabar con todo posible contradictorio» (214). En los relatos fantásticos de la era global asistiríamos, por tanto, a una coexistencia extrema de lo autóctono y lo ajeno, lo ancestral y lo ciborg, que termina por barajar las atribuciones fijas de la identidad y anular la alteridad 5 .

mundo asistimos a un proceso de transculturación, que se cumple mediante la apropiación y la aclimatación de un imaginario generado en las tierras del norte para la narración de las violencias y los traumas de la sangrienta historia latinoamericana, que también, en su mayor parte, se ha silenciado o negado (5).

4. También Zavala Medina y Sardiñas (2020) se detienen en el uso del pasado prehispánico para construir el efecto fantástico en su lectura de los dos volúmenes de la antología Ciudad Fantasma. Relatos fantasmas de la Ciudad de México. (Siglo XX-XxI), editado por Vicente Quirarte y Bernardo Esquinca. Aquí, la coexistencia de dos temporalidades antinómicas permitiría seguir reflexionando a través de lo fantástico sobre la historia de México, logrando una brillante codificación literaria de la misma, como señalan Zavala Medina y Sardiñas, retomando las consideraciones de Olea-Franco.

5. Bizzarri centra su lectura en dos autoras argentinas, Mariana Enríquez y Samanta Schweblin, cuya narrativa reposiciona la distancia entre el campo y la ciudad, casi invirtiendo los atributos de uno y otra: el campo se transforma en un espacio aséptico y postindustrial, generador de nuevos monstruos y catástrofes ecológicas, como vemos en Schweblin, y en particular en 


\section{El retorno de las brujas, o sobre la monstruosidad femenina}

Sin embargo, en esos textos donde se solapan lo fantástico y el gótico latinoamericano es posible asistir al retorno de los que llamaremos los «monstruos fantásticos locales», es decir, aquellos que tienen sus raíces en el folclore y en una variada imaginería indígena: en su figuración se cruzan la etnia, el género y la clase, con evidentes (a veces un tanto obvias) implicaciones de crítica y denuncia de la violencia y la desigualdad inherentes a la realidad latinoamericana en la que estas narrativas se inscriben. Los monstruos a los que hacemos referencia son, para retomar la definición de David Gilmore, «supernatural or mythical constructs, imaginary beings embodying human terrors and fears, fanciful organic images of evil and of mystery. Such fantasies are usually gigantic in size and therefore menacing; they are often grotesque or deformed in appearance and therefore shocking, and they produce feelings and awe and/or revulsion in onlookers» $(48)^{6}$. Las monstruosidades fantásticas y las monstruosidades reales se entrelazan, porque, como recuerda Cohen, «the monster is born [...] as an embodiment of a certain cultural moment - of a time, a feeling, and a place» (4). En este sentido, esos cuentos en los que vuelven los monstruos tradicionales, si bien no proponen una verdadera lectura desde el paradigma de la identidad, inevitablemente plantean una reflexión 'situada', enfocando los conflictos, las contradicciones, los miedos, de un determinado lugar y su cultura. Eso es lo que puede observarse en la obra de algunas narradoras contemporáneas, entre las que se encuentran las ecuatorianas Solange Rodríguez Pappe y Mónica Ojeda, quienes, junto con María Fernanda Ampuero, son reconocidas hoy en día como las propulsoras de la renovación de la literatura ecuatoriana desde una perspectiva feminista, tal como se desprende de la entrevista realizada por Marta Ailouti, «Escribir en Ecuador y ser mujer» 7 .

Si la adscripción a un territorio puede resultar más lateral en los relatos de La primera vez que vi un fantasma (2018), ambientados en un espacio anónimo -aunque indudablemente latinoamericano-, la aclimatación de las atmósferas góticas a la

Distancia de rescate (2018), mientras que el espacio urbano se contamina con las leyendas rurales y sus deidades, como ocurre, por ejemplo, en «El chico sucio» de Enríquez, donde asistimos al retorno de cultos populares, aquí al servicio del género de terror.

6. Para una definición teórica más amplia (pero de todos modos no exhaustiva) del monstruo, véanse Cohen, Gordillo y Spadaccini, Roas, Weinstock.

7. Ailouti refiere las palabras de Rodríguez Pappe: «Necesitamos romper los paradigmas de la literatura tradicional ecuatoriana que era básicamente masculina y explorar lo que las mujeres tienen que decir». Y luego la entrevistadora comenta: «La cuestión de género, que planea alrededor de toda la conversación, se vuelve inevitable entonces. La dificultad de hacerse ver, de que reconozcan su valor literario, más allá de cuestiones superficiales, de que las lean sin prejuicios les afecta particularmente a ellas, las mujeres. Ninguna de las tres escribe literatura femenina. Sus temas, desde la violencia, el miedo, las relaciones, los límites del mal, son temas universales» (Ailouti, s.p.). 
región andina es el propósito manifiesto del volumen de relatos de Ojeda, Las voladoras (2020), cuyo fil-rouge son el paisaje geográfico-cultural y los miedos de la sierra ecuatoriana, donde, como la misma autora ha comentado, «conviven lo ancestral con el presente y con el futuro. Es lo que quise que se experimentara a través de la escritura» (Gascón). Esta exploración a través de la escritura se produce tanto en Ojeda como en Rodríguez Pappe a partir del género, interpelando a monstruos femeninos e invitando a la reivindicación de una diferencia que se sitúa abiertamente bajo el signo de lo monstruoso y lo abyecto.

La problematización de la naturaleza del monstruo es central en el tríptico que componen los relatos «Las voladoras», «Sangre coagulada», "Cabeza voladora», con los que se abre Las voladoras, de Ojeda, y en «La historia incómoda que nos contó Olivia en el día de su cumpleaños» ${ }^{8}$, cuento de Solange Rodríguez Pappe. En esta peculiar relación con el monstruo es donde se encuentra el signo específico de lo fantástico «femenino» según las lecturas psicoanalíticas: Monica Farnetti considera, por ejemplo, que mientras la reacción masculina ante la aparición del monstruo (o sea, de lo ominoso por antonomasia) es típicamente angustiada, la reacción del sujeto femenino es empática, encontrando de hecho en la alianza con el monstruo una posibilidad de autonomía y emancipación respecto al discurso dominante, masculino y patriarcal, que en la tradición occidental define los límites del sujeto y de lo universal. En el caso de nuestras autoras, sin embargo, los que regresan son monstruos femeninos que, como veremos, dan lugar más que a una «relación amorosa», a una identificación monstruosa, o sea, a una apropiación de esa monstruosidad considerada exclusiva de lo femenino, cuya larga tradición es imposible reconstruir en el breve espacio de estas páginas. Barbara Creed da buena cuenta de ello en su ya clásico ensayo The Monstrous-Feminine: Film, Feminism, Psychoanalysis (1993), donde explica que lo monstruoso femenino es aquello que se caracteriza precisamente por el papel que juegan el género y las funciones reproductivas -donde residiría la marca de la diferencia femenina- en la construcción de la monstruosidad (249). Como también ha señalado Rosi Braidotti siguiendo a Creed, la monstruosidad de lo femenino depende de la naturaleza liminar del cuerpo de la mujer, a la vez faltante y excedente ${ }^{9}$, de la que también surge su representación entre lo sagrado y

8. De ahora en adelante «La historia incómoda...".

9. Tanto Creed como Braidotti retoman (para confutarlas) las posiciones freudianas sobre la envidia del pene, que sería la marca de lo femenino. Esta misma envidia del pene y su correlato, la ansiedad de castración, explicarían la reacción angustiada masculina ante el cuerpo femenino, un cuerpo 'faltante' porque sin pene, y por lo tanto monstruoso. En cambio, apoyándose en un artículo de Susan Lurie, Creed rechaza por completo la teoría freudiana de la envidia del pene y afirma que lo femenino resultaría monstruoso y amenazador para un sujeto masculino justamente porque es total y poderosamente entero: «The notion of the castrated woman is a phantasy intended to ameliorate man's real fear of what woman might do to him» (Creed 36). 
lo terrorífico: el cuerpo de la mujer embarazada se sustrae a cualquier tipo de norma y de posible control.

En Rodríguez Pappe y Ojeda lo monstruoso femenino conoce diversas personificaciones. Sin embargo, en esta ocasión decidimos enfocar en los relatos donde se entrevé a contraluz el arquetipo por excelencia de la mujer monstruosa: la bruja, figura a la vez repulsiva y seductora, como la describen los cientos de páginas de juicios por brujería recogidos en el Malleus Malleficarum (1486), el libro que ha contribuido a fijar los rasgos de las brujas de manera indeleble ${ }^{10}$. Sin embargo, no es la figura histórica lo que nos interesa investigar aquí, sino los usos literarios de esta figura, aunque somos conscientes del poder modelador que ejercen el mito y las representaciones artísticas sobre la realidad y sabemos que este imaginario ha contribuido a reforzar a lo largo del tiempo arquetipos y estereotipos de lo femenino, determinando las características de la figura histórica ${ }^{11}$. Las precursoras de las brujas modernas son las mujeres de la mitología como Eva, Lilith, Medusa, Hécate, Circe o Medea, que subyacen también a las figuraciones siniestras de la mujer que encontramos en lo fantástico hispanoamericano del siglo xx -por ejemplo, Delia Mañara, la protagonista del cuento "Circe» (Bestiario, 1951) de Julio Cortázar, o Consuelo/Aura, la protagonista de la novela corta Aura (1962) de Carlos Fuentes. Estas «brujas» literarias, sin embargo, no tienen mucho en común con las que encontramos en la narrativa de Ojeda y Rodríguez Pappe. En el cuento de Cortázar y en la novela corta de Fuentes (que se abre elocuentemente con un epígrafe tomado de La sorcière, el famoso ensayo de Jules Michelet dedicado a la bruja medieval), la focalización adopta el punto de vista de los protagonistas masculinos y la «verdad» de las enigmáticas protagonistas femeninas permanece inmersa en el misterio y la indecidibilidad. Las mujeres brujas, representadas a través de la mirada masculina, son criaturas seductoras en el sentido etimológico del término y, por lo tanto, gracias a sus personalidades magnéticas $-\mathrm{y}$ sus artes mágicos- atraen a los protagonistas, atrapándolos en una maraña indisoluble de eros y muerte. Pueden asimilarse por lo tanto a otra encarnación de la monstruosidad femenina, la que se manifiesta en el modelo finisecular de la femme-fatale. En cambio, las brujas de los cuentos de Ojeda

10. Como cuenta Caro Baroja en La bruja y su mundo (1961), las llamadas «brujas» de la Edad Media eran en realidad mujeres que no habían sido domesticadas por el orden patriarcal: a menudo vivían solas en los márgenes de la comunidad, o habían tenido hijos fuera del matrimonio y practicaban el comercio sexual. Solían ser depositarias de conocimientos y prácticas de carácter extraordinario -curaban con hierbas o ayudaban en los partos o abortos-, por lo que eran miradas con sospecha por el resto de la comunidad. Su inconformismo contenía, de hecho, la semilla del desorden, amenazando la estabilidad de todo un sistema político-económico-religioso que, como ha teorizado recientemente Silvia Federici, se fundaba precisamente en la represión de la disidencia individual y en la explotación de la fuerza reproductiva femenina.

11. Al respecto, véase Lauretis 1984, Bornay 1990, entre otros estudios. 
y Rodríguez Pappe -casi en su totalidad narrados en primera persona y con focalización interna fija en las protagonistas femeninas- exhiben toda su inhumanidad. Su anomalía física, su abyección moral, son el signo de una diferencia horrenda e insondable que actúa como fuerza catalizadora y repelente al mismo tiempo, según esa pulsión ambivalente de misterium tremendum et fascinans que la fenomenología del monstruo comparte con lo sagrado. La seducción de los cuerpos no domesticados y de los impulsos desbordados es tal que provoca una verdadera metamorfosis en las protagonistas, determinando un cambio de conciencia del que surgen, como veremos, nuevos horizontes de acción y nuevas connotaciones por la espeluznante alteridad del monstruo femenino.

\section{Entre eros y abyección: «Las voladoras», de Mónica Ojeda}

Mónica Ojeda, autora guayaquileńa afincada en Madrid, ha entrado en el panorama del terror literario en español gracias a las novelas Nefando (2016) y Mandíbula (2018), en las que, como señala Andrea Pezzé, se hace patente «una larga investigación metaliteraria sobre las posibilidades de la escritura del mal» (54). Sin duda, en Las voladoras, el primer volumen de cuentos de Ojeda, esta «escritura del mal» conoce una nueva inflexión, tanto temática como formal. La metaliteratura de Nefando, construida sobre una densa intertextualidad que dialoga en torno a los modos de escritura, es sustituida aquí por una libre reinvención de las tradiciones y leyendas del folclore andino, como queda claro desde el propio epígrafe del primer relato, «Las voladoras»: "De villa en villa, sin Dios ni Santa María. Relato oral de Mira, Ecuadon». La especificación geográfica remite directamente a una tradición popular bien determinada, que fija el ámbito en el que se desarrollan los cuentos, y más concretamente el personaje anunciado en el título, así descrito por Amanda Pico Salguero:

En Mira, ciudad ubicada en la provincia del Carchi, los relatos orales dan cuenta del personaje de la voladora, habitante de la comunidad que por la noche adquiere poderes extraordinarios. Se trata de una beldad que, ataviada de blancas vestiduras, se precipita y suspende en el aire con la principal función de transportar noticias entre los pueblos circundantes. Cuando las voladoras alzan el vuelo, su cuerpo sutil abandona la piel de la esposa, la vecina, la madre, rompe los lazos de lo real, se proyecta hacia lo insondable, maniobra con el infinito. El acto de vuelo desata resonancias, su metáfora secreta abre una puerta hacia el vacío. Refleja y disuelve límites (13).

Las otras palabras del epígrafe -o sea la fórmula mágica que permitiría a las voladoras elevarse en el aire tras frotarse con miel bajo las axilas- introducen a las atmósferas del relato (y en cierta medida de todo el libro) y señalan la infracción de los límites de moral católica que se tematiza en el cuento. Además, el fenómeno del vuelo 
nocturno aquí aludido vuelve a conectar a la voladora con las brujas de la tradición europea, llegadas a América durante la colonia a través de los espańoles ${ }^{12}$.

Los cuentos que abren la colección conforman un tríptico que exalta los atributos legendarios del arquetipo de la bruja, enfatizando tanto su íntima cercanía con la naturaleza salvaje como su sexualidad insumisa -y por lo tanto peligrosa. El eros y las distintas formas de la abyección son centrales en la reescritura que hace Ojeda de lo monstruoso femenino tanto en sus novelas -en Mandibula, por ejemplo, se aborda de manera inédita la figura maternal a través de la metáfora de las madres devoradoras- como en todos los textos de Las voladoras, estructurados en torno a la violencia patriarcal que asedia no sólo a las mujeres, sino también a la célula primordial de la sociedad: la familia. Las materializaciones de la abyección operan aquí en el nivel estético como fuerzas desestabilizadoras mediante el uso de lo horrendo y lo grotesco, como bien ha explicado Silvana Mandolessi (2012) en la estela de lo que Umberto Eco destaca en su Historia de la fealdad: lo abyecto coincide con lo feo, convergiendo hacia lo monstruoso y provocando esa respuesta ambivalente de atracción y repulsión que se manifiesta con la respuesta física del asco $^{13}$. En «Sangre coagulada», por ejemplo, la obsesión por la sangre y los fluidos corporales -especialmente los coágulos de sangre menstrual- denuncia la anormalidad de la protagonista, que se dedica junto con su abuela a hacer abortar las chicas del vecindario, en una especie de proceso de aprendizaje de bruja que la sitúa en un territorio liminal e ilegal, indudablemente marginal; en "Cabeza voladora» lo abyecto se manifiesta a través del asesinato por parte del padre de la joven Guadalupe, y en particular con el macabro hallazgo de su cabeza envuelta en el plástico, pateada durante días por el asesino como una pelota.

La voladora exhibe pues los rasgos de la monstruosidad, como explica la narradora en el íncipit del cuento homónimo («Verá, es cierto que las voladoras no son mujeres normales. Para empezar tienen un solo ojo. No es que les falte uno, sino que

12. Como aclara Pico, «las brujas de América, como personajes literarios de la cultura popular, resultan de una amalgama entre el prototipo heredado de España en la época colonial - principalmente el de la Celestina- y los seres maravillosos y terribles de nuestras tierras. La voladora de Mira es un personaje dinámico que posee los rasgos poderosos y enigmáticos de la bruja, las características fantásticas y la belleza del hada, el prodigio del ser sobrenatural y la secreta faz de la esposa» (44).

13. Esta reivindicación de lo abyecto como ideal estético es la que marca, en cierta medida, la producción de innumerables autores de la literatura contemporánea no mimética, protagonizada por corporalidades monstruosas. Señala Mandolessi sobre la asociación «abyección», «feo», "asco»: «La enfermedad, la vejez, la decadencia, el cadáver y la muerte, el cuerpo en su materialidad, la demonización del enemigo que retrata como feos a grupos o etnias sociales (los extranjeros, los judíos, los negros), la perversión y el gusto por la crueldad (encarnados en personajes ejemplares como Sade o Gilles de Rais). Así aquello que provoca la emoción de asco, y aquello que se representa encarnando las cualidades de lo feo, se presentan indisolublemente ligados.» (53). 
solo tienen un ojo, como los cíclopes», 12), y se retrata como una presencia de la que irradia una fuerza erótica primigenia que penetra, se insinúa "como un zumbido", hasta quebrar el equilibrio familiar, como se repite insistentemente en el texto:

A papá le disgusta su olor a vulva y a sándalo, pero cuando mamá no está le acaricia el lomo y le pregunta cosas muy difíciles de entender y de repetir. En cambio, si mamá está presente, él intenta patearla para que salga de la casa, le escupe, se saca el cinturón y golpea las puertas y las paredes como si fueran a gemir (12).

Yo no entiendo por qué mamá la odia y a la vez la observa con las mejillas rojas y calientes. No entiendo por qué a papá se le tensa el pantalón (13).

La siento acurrucarse entre mis piernas en las madrugadas y me abrazo a ella porque, como dice papá cuando mamá no lo ve, un cuerpo necesita a otro cuerpo, sobre todo en la oscuridad (12).

La leyenda tradicional no hace mención de esta pronunciada sensualidad, pero la hipersexualización de la voladora es funcional al núcleo secreto de la historia que estamos escuchando, e insistimos en el componente de escucha porque el énfasis en el íncipit está puesto abiertamente en la voz: «¿Bajar la voz? ¿Por qué tendría que hacerlo? Si uno murmura es porque teme o porque se avergüenza, pero yo no temo. Yo no me avergüenzo» (11). La referencia a la voz alta, además de constituir una pista de la metamorfosis de la protagonista que tendrá lugar en el final, sirve de hecho para subrayar la ficción de oralidad del relato. Este se presenta como una confesión dirigida a un «usted» explícito en el texto, un narratario anónimo que debe informar sobre el contenido de la confesión a los miembros de una "congregación" (14), de la que, es de suponer, forma parte también la familia de la narradora. La confesión tiene que ver con esa "verdad» que se menciona textualmente y que, de todos modos, permanece inaccesible al lector porque sólo puede expresarse a través de lo no verbal: «Si quiere que se lo explique bien, míreme. En mi cara está toda la verdad, la que no tiene palabras sino gestos. La que es materia, la que se escucha y se toca» (12).

En realidad, todo el cuento avanza por sugerencias, asociaciones, más que por rigurosas deducciones lógico-verbales. ¿Cuál es entonces el objeto de esta confesión? ¿Y de qué manera está involucrada la voladora? El íncipit in medias res y la presencia de un narratario anónimo acentúan el carácter elíptico de la narración, que procede a través de metáforas y analogías. Todas conectan el mundo rural, familiar y católico al que pertenece la protagonista (la casa) con el mundo natural y salvaje al que pertenece la voladora (el bosque), en otras palabras, la esfera de lo humano y la de lo no humano:

lo que quiero es ir hacia arriba, ¿sabe?, como una nube (11).

La voladora tiene el pelo negro, ¿`sabe?, como el mío y como el canto de los pájaros del monte (12). 
yo dejo las ventanas abiertas por la noche para escuchar el rezo de los árboles (12).

Usted no sabe lo que es amar un pelaje como si fuera un cabello (12).

...mis pezones, grandes y oscuros como los rezos de los árboles, despertaron (14).

Asistimos a un intercambio de atributos que va difuminando el límite entre el espacio amenazador y monstruoso de las voladoras y el mundo humano, claramente regido por Dios.

Las elipsis, las analogías, las repeticiones, junto con las imágenes oníricas y nocturnas intencionadamente herméticas ${ }^{14}$, hacen que el relato proceda por asociaciones y fragmentos lógicos, que sin embargo puede tratarse de recomponer mediante, como decíamos al principio, una escucha atenta. El campo semántico del sonido -introducido desde el principio a través del énfasis en la voz de la narradora y en la naturaleza oral del relato- contribuye a tejer una de las tramas de la significación y conecta de nuevo con el mundo de las brujas, tradicionalmente asociado a un universo sonoro dionisiaco (Caro Baroja). El campo semántico del sonido está presente bajo diferentes maneras, pero no todas las referencias al sonido pueden interpretarse claramente porque están filtradas por la mentalidad mágica de la realidad textual, y transformadas por una imaginación metafórica y simbólica que no admite interpretaciones unívocas:

14. Por ejemplo: «Yo soñé con una de ellas antes de que entrara a nuestra casa por la ventana de mi habitación. La vi sentada, rígida, dándole de beber sus lágrimas a las abejas. Pocos saben que las voladoras pueden llorar, y los que saben dicen que las brujas no lloran de emoción, sino de enfermedad» (12). O, más abajo, en la misma página: «en mis sueños, la voladora tiene un paisaje y una tumba. Tiene montańas y un muerto al que llorar. Yo nunca he sabido por qué llora ni por qué sus lágrimas sirven de aliento para el zumbido divino. ¿Sabe usted que el sonido que hacen las abejas es la vibración de Dios?» (12-13). Dejamos para otra ocasión la reflexión sobre la simbología de las abejas, insectos que desde el mundo antiguo, pasando por los bestiarios medievales y los tratados religiosos del siglo XVI hasta las lecturas de Bernard Mandeville y Karl Marx, para ceñirnos al mundo occidental, han tenido muchísimas interpretaciones. De manera general, podemos recordar que las abejas fueron un ejemplo perfecto de ginecocracia y castidad, y estaban asociadas a tres divinidades femeninas: Artemis, Deméter y Perséfone, «la primera por su actividad incesante, habilidad y destreza; la segunda por su representación de la maternidad y la fertilidad; la tercera por sus connotaciones de carácter ctónico» (Fernández Uriel 195). Agregamos que para la religión católica eran símbolo de pureza. Igual de compleja resulta la simbología de la miel, tan rara y preciada de considerarse comida de los dioses, también connotada de manera ambivalente: si bien posee rasgos ctónicos (en naturaleza, los panales se encuentran en la cavidad de los árboles) vinculándose con el imaginario de la muerte, la miel está también asociada a la palabra de los poetas y al saber profético. Las abejas y la miel evocan un conjunto de elementos sumamente sugerentes que se proyectan sobre la voladora, abriendo la posible connotación de este personaje a múltiples resonancias. 
La voladora entró llorando con su único ojo y trajo los zumbidos a la familia. Trajo la montańa donde jadean las que aprendieron a elevarse de una forma horrible [...] (12).

En secreto, yo dejo las ventanas abiertas por la noche para escuchar el rezo de los árboles. Los oigo y me arrullo con ellos aunque a veces también me da escalofríos el negro fondo de sus oraciones (12).

«No queremos su silencio». Y es que ella mira a mamá con su único ojo sin hablar (13).

Según mis padres [el bosque, N.d.A.] es un templo de sonidos terribles, de ruidos de pieles, uñas, picos, colas, cuernos, lenguas, aguijones... (13).

lo que más me da miedo es el sonido de las plantas. Esos crujidos verdes que llaman a la voladora y la alejan de mis caderas (13).

Si he abundado con las citas es porque considero que permiten ilustrar acertadamente las distintas reacciones de los miembros de la familia ante el acontecimiento extraordinario (y percibido como tal en el relato) que es el motor de la acción narrativa: la entrada de la voladora en la casa, es decir, la invasión del espacio propio y ordenado por el caos sagrado ${ }^{15}$, que se anuncia con un sonido, continuo y penetrante, «el zumbido». Mientras que la madre siente un silencio inquieto y el padre los «sonidos terribles» del bosque, la nińa está atenta a los sonidos imperceptibles de las plantas, «los rezos de los árboles». A la hostilidad de la madre (silencio), se opone el impulso ambivalente del padre, atraído por la voladora y al mismo tiempo aterrorizado por esta atracción (como subraya la afirmación sobre los ruidos del bosque, descrito como un lugar infernal). La chica, en cambio, desea la cercanía de la voladora, declara amarla. He aquí el primer gran conflicto de la historia, verbalizado por la narradora: «¿Qué se hace cuando una familia siente cosas tan distintas y tan similares a la vez? Yo rezo hacia arriba y el ojo de la bruja se tuerce. Suben las abejas» (15).

Se activan de esta manera en el texto las dos acepciones del verbo «sentir», oír con el oído y experimentar una impresión; lo que se escucha, como dijimos, refleja lo que se experimenta, es decir, los efectos de la cercanía con lo no humano, sea monstruoso, sea sagrado, ya que las pulsiones inconfesables y ominosas que constituyen el secreto del relato deben expulsarse afuera de los espacios del Yo. Por esta razón, se atribuyen siempre al Otro, es decir, a la dimensión no humana con la que se confrontan los personajes del relato, o sea la voladora, pero también Dios. Como sostiene el padre de la narradora, Dios puede enloquecer los caballos domesticados y empujarlos a traspasar las vallas que separan la casa y el bosque: "Cuando un

15. Retomando las palabras de Timothy Beal sobre la naturaleza sagrada y demoníaca del monstruo, podemos decir que "The monster is an envoy of the divine or the sacred as radically other than 'our' established order of things. It is an invasion of what we might call sacred chaos and disorientation within self, society and world» (298). 
caballo enloquece, papá dice que es porque el-Dios-que-está-en-todo despierta en el corazón del animal» (13). Del mismo modo, inferimos, es Dios el que empuja hacia el bosque metafórico de la sensualidad abyecta a los seres humanos: «'Si algo tan grande como Dios abre los ojos tras tus huesos, tú te disuelves como polvo en el agua y dejas de existir', me dijo» (13). La analogía entre la voladora y Dios se sugiere a través de otra metáfora auditiva, que permite avanzar en las asociaciones de la narración: «¿Sabe usted que el sonido que hacen las abejas es la vibración de Dios? Mamá le teme a los panales por esto» (13). Se introduce así otra combinación lógica (voladora - zumbidos - sonido de las abejas - vibración de Dios) que desemboca en una identificación sorpresiva:

Pero la voladora es el bosque entrando a nuestra casa y eso no había pasado nunca. Nunca habíamos sentido el delirio divino tan cerca, ni tampoco su deseo. Porque en el fondo, créame, yo le estoy hablando del deseo de Dios: el misterio más absoluto de la naturaleza. Imagine ese misterio entrando a su casa y ensanchándole las caderas. Imagine a las plantas sudando. Imagine las venas brotadas de los caballos. La voladora hace que papá se manche los pantalones y que mamá cierre muy fuerte las piernas. Hace que yo me unte las axilas con miel y suba al tejado a probar el aire. A pesar de eso la amamos y el amor tiene su propia forma de conocer, ¿entiende? (13-14).

La monstruosidad de la voladora consiste en ser un misterio insondable, así como la fuerza del deseo erótico que se le revela a la niña en el momento de su primera menstruación -mencionada en el relato- convirtiéndola en objeto de deseo para su padre. Llegamos pues al secreto de la confesión y del cuento, que nunca se hace explícito en el texto -innombrable como el tabú que evoca- aunque la insistencia en términos e imágenes que recuerdan la sexualidad insinúa ciertas interpretaciones:

Y después de unos meses yo empecé a hincharme y todos los caballos enloquecieron. Todas las cabras durmieron. Usted tiene que explicarle a la congregación que esto fue lo que sucedió: que a papá le turbaba que yo durmiera con el zumbido de las abejas. Sudaba. Se tocaba debajo de los pantalones. Mamá, en cambio, se cortó el pelo y lo enterró al pie del manzano más viejo del bosque (14).

Las lágrimas mojan mi cuerpo por la noche. Todavía duermo con la voladora y, a veces, papá mira igual que un caballo en delirio la línea irregular de la valla que separa nuestra casa del promontorio (15).

«Las voladoras» puede entenderse como un relato de transición en un momento de metamorfosis de la infancia a la edad adulta, cuando el cuerpo femenino sufre las profundas modificaciones que preparan a la posibilidad de procrear y abren las puertas a otras dimensiones de lo femenino. Es el encuentro con la pujanza de lo monstruoso femenino que la voladora encarna lo que produce, entonces, un cambio de conciencia que permite liberarse de la opresión de la moral y de los modelos de un sistema heteronormativo: «Yo no me avergüenzo del tamańo de mis caderas. No 
bajo la voz. No le tengo miedo al pelaje. Subo al tejado con las axilas húmedas y abro los brazos al viento. El misterio es un rezo que se impone» (15).

El monstruo mantiene su carácter terrorífico, pero es objeto de una re-significación subversiva que convierte su monstruosidad en una posibilidad inédita de afirmación de los sujetos oprimidos -como la joven protagonista de este relato- a través de la apropiación de una chocante alteridad. Para este objetivo, Ojeda diluye hábilmente las fronteras entre lo humano / lo inhumano, lo puro / lo impuro, el bien / el mal, y dentro de esta mezcla y disolución de límites nos cuenta cómo y por qué se llega a desafiar el orden cultural dominante y optar orgullosamente por devenir un «monstruo femenino».

\section{Monstruos femeninos y horrores cotidianos: «Cabeza voladora» $\mathrm{y}$ «La historia incómoda que nos contó Olivia en el día de su cumpleańos»}

La reivindicación de la monstruosidad se convierte entonces a menudo en una solución inevitable ante la violencia perpetrada contra las mujeres por el orden patriarcal. A veces, la identificación de las protagonistas con lo monstruoso provoca desenlaces extremos y controvertidos, como puede verse, por ejemplo, en otro cuento que tematiza el regreso de las brujas, "Las cosas que perdimos en el fuego» (Las cosas que perdimos en el fuego, 2016), de Mariana Enríquez. Para denunciar a través de la ficción un horror del mundo real, el feminicidio, Enríquez construye un mundo anti-utópico donde las mujeres prefieren quemarse voluntariamente en hogueras clandestinas (parodias de las quemas de la Inquisición), antes que ser quemadas por los hombres. Se trata, como anticipamos, de una solución paradójica porque la que se alcanza es una libertad abstracta, que se paga a caro precio... La ficción subversiva de Enríquez estira los límites de la realidad y los deforma mediante la paradoja, pero no abandona los territorios de lo real. En cambio, en «Cabeza voladora», de Ojeda y «La historia incómoda...», de Rodríguez Pappe, la representación de la violencia se realiza a través de lo fantástico, así como lo han teorizado Rosalba Campra y David Roas, es decir, como la irrupción de lo imposible en lo real, provocando la convivencia conflictiva de dos órdenes cuyas leyes son distintas e incompatibles. Esta convivencia conflictiva es la que se plantea también en los cuentos de Ojeda y Rodríguez Pappe a fin de crear otra percepción de lo real y sus horrores: ambas autoras narran crímenes que se desarrollan en un entorno urbano latinoamericano globalizado, pero acuden al imaginario de los monstruos folclóricos para articular de manera más poderosa y más visionaria su denuncia, que aborda otra vez ámbitos íntimos y cotidianos como la pareja y la familia.

«Cabeza voladora» declara su vinculación con el folclore andino desde el título: el motivo de la cabeza que se desprende del cuerpo y sale a volar de noche remonta probablemente al pasado prehispánico e indígena, pero mantiene su vitalidad en las narrativas amerindias actuales, como prueba la gran variedad de versiones en las que la leyenda de las cabezas voladoras ha sido transmitida hasta el siglo xx, 
según refieren Efraín Morote Best y Sirley Ríos Acuña ${ }^{16}$. En el relato de Ojeda, en particular, nos encontramos ante la aparición de las umas, brujas que se quitan la cabeza (de día martes y viernes, como puntualizan los relatos tradicionales) «para deambular por las calles mientras su cuerpo hace chillidos horribles» (Ríos Acuña, 108). La cabeza voladora del folclore y la cabeza «voladora» del cuento se superponen, puesto que, como se ha dicho, se relata el hallazgo por parte de la protagonista de la cabeza de una adolescente, decapitada por el padre. El acento se pone por lo tanto de forma explícita en la estética de la abyección que mencionamos antes, esta vez a través de imágenes cuyo carácter alucinado refleja el fuerte trauma vivido por la protagonista y el salvajismo del crimen cometido:

La madrugada anterior había sońado con su torso moreno y menudo bailando en medio de la selva, agitándose, sacando las costillas y los pequeños senos. Era un torso flotante que brillaba como una luciérnaga, que ascendía hacia las altas ramas de un árbol de sangre (33).

Si cerraba los ojos, ella veía la cabeza volar hacia su patio y dar dos botes sobre la tierra. Era una visión más que un recuerdo porque la cabeza tenía el tamaño de una semilla de aguacate, y luego la enterraba y la regaba y la veía crecer en un árbol con cabellos negros que parecían columpios (35).

Las descripciones de las extremidades del cuerpo enterrado, la crueldad del asesinato, las alusiones a la (perversa) atracción sexual de la protagonista hacia la adolescente asesinada, las imágenes que remiten a la materialidad del cuerpo en descomposición, constituyen una urdimbre en la que se teje un tipo de monstruosidad natural que prepara el advenimiento de la monstruosidad fantástica. La transgresión de lo real se manifiesta a través de la aparición de un grupo de brujas andinas, las umas, que se reúnen todas las noches en aquelarre en la casa, ahora deshabitada, de la joven asesinada y a las que, abandonando sus miedos, finalmente se unirá también la protagonista, convirtiéndose ella misma en una cabeza voladora.

16. Efraín Morote Best enumera los elementos recurrentes en las narrativas sobre las cabezas voladoras: «1. La cabeza de ciertas personas se desprende del cuerpo. 2. Las causas del desprendimiento son varias (la calidad de ser bruja la persona, el hecho de mantener relaciones incestuosas, la sed con que a veces se duerme, etc.). 3. La cabeza se desplaza (volando, dando tumbos, etc.). 4. Busca lugares donde realizar ciertos actos (muladares, sitios donde hay aquelarres, sitios donde hay agua, ceniza o carbón, etc.). 5. Es un ser peligroso (pasa por 'entre' las piernas y causa la muerte, puede adherirse y hacer vida orgánica con los cuerpos de hombres y animales, chupar la sangre, etc.). 6. Hay ciertas maneras de romper la posibilidad de reintegración de la cabeza al cuerpo (tocando al cuerpo, pasándole ceniza, tapando con una mate o marlo, etc.). 7. Se puede atrapar las cabezas (con ramas espinosas, etc.). 8. Raras veces se produce el desplazamiento de los intestinos, el estómago u otras partes del cuerpo. 9. El personaje toma diferentes nombres, según las regiones. 10. Representa una supervivencia de la época incaica con numerosos elementos derivados de la cultura occidental» (123-124). 
El relato, pues, cuestiona la identidad de los monstruos, mejor dicho, se pregunta y nos pregunta quiénes son los verdaderos monstruos, sugiriendo -de manera tal vez un poco esquemática- la respuesta. Según el modelo que observamos en «Las voladoras», ante la constatación de una monstruosidad inherente a la realidad y a la cultura dominante, no queda otra que optar por la metamorfosis en lo monstruoso sobrenatural, hundirse en la alteridad y reconocer la propia monstruosidad, y a través de la alteridad misma liberarse de los miedos y las ansiedades y empoderarse, como se lee en las líneas finales del cuento:

Bajó la mirada y vio su cuerpo caído sobre la tierra, flojo y pálido como el capullo roto de una crisálida. Sus ojos estaban lejos, a la altura de diez, quince, veinte cráneos flotantes. Su voz era viento.

Aterrorizada, escuchó el ruido de una cabeza siendo pateada contra la pared como el futuro. Y luego, abriéndose paso entre la ingravidez de los cabellos, el sonido de la suya propia volando hacia el patio de al lado y cayendo en las hortensias (43).

El reconocimiento en la alteridad monstruosa femenina cierra también «La historia incómoda...» de Rodríguez Pappe, autora de casi una decena de libros que exploran las distintas formas de la literatura no mimética, en la que se cruzan los territorios de lo fantástico, el terror, lo gótico. Sobre la colección de cuentos que nos ocupa, La primera vez que vi un fantasma, Victor Manuel Sanchis Amat comenta: «su objetivo esencial radica en la indagación intimista de unos fantasmas interiores que alegorizan los miedos que conforman la identidad personal de los personajes femeninos que protagonizan las historias y el contexto social en el que habitan» (160). A través de una somera mirada a los otros relatos del libro es posible reconocer la tensión hacia la subversión de los estereotipos de género que subyace a la poética de la autora, y de hecho casi todos los relatos están protagonizados por mujeres: en "Instantánea borrosa con luna» y «Matadora», las protagonistas experimentan asombrosas metamorfosis hacia lo animal, gracias a las que logran vencer los lugares comunes machistas y las violencias que las obligan a vivir acorraladas por el miedo, en «Paladar» se alegorizan los equilibrios de la pareja a través de una historia de engaños y canibalismo, en «Pequeñas mujercitas» se ironiza sobre el deseo sexual mediante la invención de mujeres de minúsculo tamaño que no tienen problemas en gozar libremente de su sexualidad y se trepan por el cuerpo del hermano de la narradora...

La conexión «fantasmas interiores» "contexto social» planteada por Sanchis Amat es también muy evidente en "La historia incómoda...», donde la figuración de la monstruosidad sobrenatural se entrelaza no sólo con la violencia de género sino también con la desigualdad social que habita el escenario urbano en el que se mueve la protagonista. La estructura espacial típica del relato fantástico, que se funda en la presencia de umbrales y fronteras cuya transgresión desata el hecho irracional, se adopta ahora para reflejar la organización clasista de la ciudad, saturada de fronteras sociales: «Para morirse de vergüenza ya está la ciudad. Ya ven que uno cruza 
el puente y todo son penurias. Es lamentable lo que se ve en los semáforos, y peor para la época en que se acerca Navidad, con toda esa gente que sale de no sé dónde a pedir dinero» (73); "Pero lo más importante de todo es que yo me sentía aún a salvo, porque de este lado del puente jamás vimos ningún indigente. Qué iban a atreverse a venir. Pero nada se puede contener perpetuamente» (80).

La voluntad de distinción social es el eje central de la caracterización de la narradora del cuento, quien ostenta no pertenecer al ejército de desposeídos que diariamente recorre las calles de la ciudad, asimismo no se deja conmover por la pobreza que desfila ante sus ojos: «Hordas de mujeres embarazadas, medio vestidas arrastrando a sus hijos más chicos del brazo, golpeando los vidrios, pidiendo limosna, insistiendo con la cara sucia. Por más que uno niega con la cabeza y quiere no mirarlas, ellas insisten como almas en pena. Son viajes largos, largos y la tortura llega en cada semáforo» (73).

El cuento describe así un proceso de «monstrificación» social que enfatiza la valla entre los ricos y los pobres, transformando la ciudad en un lugar apocalíptico: «En el centro, bajo las casas, no hay un solo portón libre, todos están invadidos por cartones y sábanas agujereadas de cuyos bordes asoman pelos, ojos, pies sucios. Da la impresión de que todos en el mundo han muerto y solamente ellos han sobrevivido al Apocalipsis» (75). Se anuncia así el retorno de los monstruos...

En realidad, este horror a los indigentes - generador de otra clase de monstruoses en cierta medida una máscara para marcar una distancia aparentando un estatus que no se posee. Como descubriremos a lo largo del relato (que se presenta como el discurso que Olivia hace a los invitados durante la fiesta de su cumpleaños, o sea como otra ficción de oralidad), la narradora es víctima del sistema que ella misma defiende, un sistema basado en la ostentación de riqueza, belleza, juventud: trabaja en una agencia de viajes donde le instan a que sea siempre sonriente y bien maquillada, es viuda pero se ha casado de nuevo con un hombre divorciado que tiene un hijo adolescente consentido y tiránico, Huguito. Además, su vida conyugal es muy estéril: su esposo no tiene en cuenta sus deseos - por ejemplo, tener otro hijo- ni se percata de sus inquietudes. En este sistema cerrado, vacuo, frívolo, sucede la irrupción de un elemento imprevisto e inexplicable: la aparición de «una mujer con el pelo blanco hecho una maraña sucia, una anciana doblada hurgando en la basura. Algo que con pena vemos y no vemos todos los días» (77). El tema de la condición de aparecidos de los tantos desposeídos que pueblan las ciudades latinoamericanas se revela decisivo en el desarrollo narrativo del personaje de Olivia y en la constitución del sentido general. Olivia es obligada a enfrentarse con la doble alteridad que, en su opinión, la anciana mujer encarna. Esta, además de poseer todos los atributos del «monstruo social» que se mueve en los límites de lo habitable (hurga en la basura, es sucia), posee también los atributos del monstruo sobrenatural: "caminó con una velocidad incomprensible hasta la ventana de mi auto y la tocó con su puño mugriento. La tocó tres veces como quien toca una puerta esperando que lo dejen 
entrar, la tocó para entrar en mi vida» (78). El encuentro con esa mujer «horrenda, tal vez no horrenda, sino ilógica, enfermiza» (78), se convierte en una suerte de hechizo que conduce a la narradora al borde de la locura. Esta misma vacilación de la razón es también la causa de la metamorfosis que se constituye como hecho central del relato, lo cual permite asemejarlo a los otros cuentos de Ojeda considerados para este estudio.

Como las protagonistas de Ojeda, también para Olivia la aparición del monstruo es el encuentro con lo impensable y lo imposible, lo espeluznante y lo inclasificable, una "cosa inaudita» (78) que atrae y repele al mismo tiempo: «Lo que vi, esa cosa inaudita, desde ese primer contacto me dejó pensando en ella, esperaba topármela y a la vez lo temía: era como el amor, pero al revés [...] La recordaba con un placer vergonzoso y a la vez con miedo. Era como presionar con la uńa una herida para ver si aún duele y tiene pus» (78). Sin embargo, el trastorno que provoca la cercanía con la naturaleza extraordinaria y tremenda del monstruo es siempre revelador de algo, conlleva una epifanía sobre un saber que ha sido expulsado de la cultura oficial, y que los monstruos vuelven a hacer patente. Para conocer más sobre la identidad de la anciana mujer, Olivia empieza a estudiar folclore latinoamericano y se entera así de la existencia de un amplio panteón de divinidades femeninas que ofrecen protección o venganza: la Sayona, espíritu de mujer que se les aparece solo a los hombres que mantienen relaciones extra-conyugales; la Patasola, monstruo de una pata sola que se les aparecería a los hombres cuando están pensando lascivamente en una mujer; la Tunda, que atrapa a los hombres en la selva; la Siguanaba o Cigua, otro espíritu femenino que puede cambiar de aspecto para seducir a los hombres, y muchas otras «brujas» autóctonas que subvierten la condición de sumisión de la mujer en el sistema de los géneros.

La anciana aparecida del relato de Rodríguez Pappe propicia una toma de conciencia en dos niveles: de clase y de género. Por un lado, la narradora se da cuenta de que «todas las ciudades están construidas sobre huesos y cementerios, así que, de cada cinco habitantes, uno es un fantasma» (79). Se trata, por lo tanto, de un despertarse a la verdad terrorífica de la historia y del mundo, asimismo al horror inherente a cierto orden social que solo se puede cuestionar mediante el punto de vista subversivo que ofrece la locura, desatada por el encuentro con el monstruo. Todo el resto -el entorno en que se mueve la protagonista- es una ficción social basada en la mentira y la dominación patriarcal: Olivia es engañada por su pareja, que la traiciona con la ex esposa, es maltratada por parte del hijo de él, que la atemoriza con sus caprichos, y es ofendida por parte de su jefe, que le reprocha constantemente por su edad y su aspecto. Llegamos así a la otra toma de conciencia que los monstruos femeninos proporcionan, la de género, tanto que en el final la protagonista y otro monstruo fantástico femenino establecen una alianza: Olivia le cede el terrible Huguito a la mujer del saco, que es, por supuesto, la versión femenina del hombre del saco, quien según la leyenda se lleva en su saco a los niños malos. 
La afiliación a la familia de los monstruos se da también bajo otra forma: en el final aprendemos que la narradora -que, pese a su edad, ha quedado milagrosamente embarazada - ha festejado su cumpleańos con copas de champán envenenado para matar a su marido y a su amante y ahora se prepara a vivir una nueva vida bajo el sello de lo monstruoso: «Los monstruos, cuando nos encontramos, jamás volvemos a estar solos» (87). Así se cierra el cuento, así Olivia sale de escena, hacia su porvenir. El encuentro con las figuras femeninas de la monstruosidad, para las protagonistas de los relatos que analizamos, no desemboca en la parálisis o la aniquilación en un tempo estancado que se repite cíclico, como le tocaba a la «circe» de Cortázar, Delia Mañara, o a Aura/Consuelo, la bruja de Fuentes. El encuentro con las brujas tradicionales «trae el futuro» (Ojeda 14), como comenta la narradora de «Las voladoras».

Como se ha visto, todos estos relatos problematizan la naturaleza del monstruo fantástico, a través de unas preguntas fundamentales: ¿quiénes son realmente los monstruos en estas historias? ¿Cuánta monstruosidad diariamente aceptamos sin darnos cuenta? ¿De qué monstruosidades somos cómplices? Interrogantes que, ante las desigualdades siempre más acentuadas en el mundo globalizado post-industrial, no pueden dejarnos tranquilos. Es evidente que en un mundo sin justicia y sin héroes, donde la violencia cotidiana produce más y más horrores (naturales), los monstruos, y sobre todo las monstruas, han dejado de ser antagonistas y se han puesto al servicio de "un uso feminista de lo fantástico», como David Roas lo ha llamado, en el que la reivindicación de la monstruosidad desde el género -y el feminismo- juega un papel fundamental. Así, estas ficciones fantásticas llevan a cabo un gesto doblemente subversivo: no solo contribuyen a la actualización de las connotaciones del monstruo y a su caracterización estético-literaria, que cambia según cambian los miedos y las contradicciones del tiempo que este habita, sino que, a través del reconocimiento en lo monstruoso femenino, dibujan nuevos modelos y nuevos posibles imaginarios para las mujeres, provocando otro decisivo efecto que también «trae el futuro»: la deconstrucción de los estereotipos de género y de su naturalización.

\section{Referencias bibliográficas}

Ampuero, Fernanda, Ojeda Mónica, Rodríguez Pappe, Solange. «Escribir en Ecuador y ser mujer». Entr. Martha Ailouti, El Cultural, 8 Mar 2019. https:/elcultural.com/ escribir-en-ecuador-y-ser-mujer. Consultado el 2 Mar 2021.

Beal, Timothy. «Introduction to Religion and its monsters». Jeffrey Andrew Weinstock (ed.). The Monster Theory Reader. Minneapolis: University of Minnesota Press, 2020: 295-302.

BizzARri, Gabriele. «Fetiches pop y cultos transgénicos: la remezcla de la tradición mágico-folclórica en lo fantástico de lo global». Brumal, VII:1, (2019): 209-229. https:// revistes.uab.cat/brumal/article/view/v7-n1-bizzarri. Consultado el 2 Mar 2021. https:// doi.org/10.5565/rev/brumal.561

Bornay, Erika. Las hijas de Lilith, Madrid: Cátedra, 1990. 
Braham, Persephone. From Amazons to Zombies. Monsters in Latin America. Lanham (Maryland): Bucknell University Press, 2015.

Braidotti, Rosi. Madri, Mostri, Macchine. Roma, Manifestolibri: 2005.

Calvo-Díaz, Karen. "Demonios latinos: el mito prehispánico indígena como motivador gótico en el relato mexicano contemporáneo», Brumal, 6:2, (2018): 345-366. https:// revistes.uab.cat/brumal/article/view/v6-n2-diaz. Consultado el 2 Mar 2021. https:// doi.org/10.5565/rev/brumal.426

Calvo-Díaz, Karen. "Ciudad, terror y mito: la concepción del gótico literario desde el mito prehispánico en los cuentos 'La llorona' de Artemio del Valle-Arizpe 'La fiesta brava', de José Emilio Pacheco, y 'Año cero' de Bernardo Esquinca». Mitologías hoy, 19, (2019): 195-213. https://revistes.uab.cat/mitologias/article/view/v19-calvo. Consultado el 2 Mar 2021. https://doi.org/10.5565/rev/mitologias.615

Campra, Rosalba. Territorios de la ficción. Lo fantástico. Sevilla: Renacimiento, 2008.

Caro Baroja, Julio. La bruja y su mundo. Madrid: Alianza, 1973.

Casanova Vizcaíno, Sandra, Ordiz, Inés (eds.). Latin American Gothic in Literature and Culture. New York: Routledge, 2018.

Cohen, Jeffrey Jerome. «Monster Culture (Seven Theses)». Jeffrey Jerome Cohen (ed.). Monster Theory: Reading Culture. Minneapolis: University of Minnesota Press, 1996: 1-25. https://doi.org/10.5749/j.ctttsq4d

Cortázar, Julio. Cuentos completos. 2 vols. Madrid: Alfaguara, 1998.

Creed, Barbara. The Monstrous-Feminine: Film, Feminism, Psychoanalysis. New York and London: Routledge, 2015. Ebook.

Edwards, Justin D., Guardini Vasconcelos, Sandra (ed.). Tropical Gothic in Literature and Culture. New York and London: Routledge, 2016.

EnríQuez, Mariana. Las cosas que perdimos en el fuego. Barcelona: Anagrama, 2016.

Farnetti, Monica. "Le amiche del Mostro». Giorgio Rimondi (ed.). Lo straniero che è in noi. Sulle tracce dell'Unheimliche. Cagliari: Cuec, 2006: 69-78.

Federici, Silvia. Calibán y la bruja. Mujeres, cuerpo y acumulación primitiva. Madrid: Traficantes de sueños, 2019.

Fernández Uriel, Pilar. "Algunas anotaciones sobre la abeja y la miel en el mundo antiguo». Espacio, tiempo y forma. Serie II. Historia Antigua. 1, (1988): 185-208. http:// revistas.uned.es/index.php/ETFII/article/view/4121/3962. Consultado el 2 Mar 2021.

Fuentes, Carlos. Los días enmascarados. México: Era, 1982.

Fuentes, Carlos. Aura. México: Era, 2001.

Giallongo, Angela. "Medusa, Eva y Coatlicue en el imaginario europeo de los siglos de la Conquista». Revista Internacional de Cultura y Literatura. 2018. https://revistascientificas.us.es/index.php/CulturasyLiteraturas/article/view/4784. Consultado el 2 Mar 2021.

Gilmore, David. «Monster and Man in Spain». Lo sguardo.net, Rivista di Filosofia. IX/12, 2, (2012): 47-61. http://www.losguardo.net/wp-content/uploads/2015/12/Spazi_del_ mostruoso.pdf. Consultado el 2 Mar 2021.

Gordillo, Adriana, Spadaccini, Nicholas. "Introduction. Reading Monsters in Iberian and Spanish American context». Hispanic Issues On Line, 15 (2014): 1-11. https://hdl. handle.net/11299/184497. Consultado el 2 Mar 2021.

JaCkson, Rosemary. Fantasy. A literature of perversion. New York and London: Routledge, 1981. 
Lauretis, Teresa de. Alicia ya no. Feminismo, semiótica y cine (Feminismos). Madrid: Cátedra, 1984.

Mandolessi, Silvana. Una literatura abyecta. Gombrowicz en la literatura argentina. Amsterdam: Rodopi, 2012. Impr.

Morales, Ana María. «Identidad y alteridad: del mito prehispánico al cuento fantástico». Hipertexto, 7, (2008): 68-76.

Moraña, Mabel. El monstruo como máquina de guerra. Madrid/Frankfurt am Mein: Iberoamericana/Vervuert, 2017.

Morote Best, Efraín. «Cabezas Voladoras». Perú Indígena, IV: 9, (1953): 109-124. http:// repositorio.cultura.gob.pe/handle/CULTURA/1084. Consultado el 2 Mar 2021.

Nallim, Alejandra. "El gótico litoraleño de Selva Almada». En Adriana Goicochea (ed.). Miradas góticas. Del miedo al horror en la literatura argentina actual. Viedma, España: SMBlanco, 2021:77-84. https://issuu.com/etiquetanegracontenidoscultura/docs/miradas_goticas. Consultado el 2 Mar 2021.

Ojeda, Mónica. Nefando. Barcelona: Candaya, 2016.

OJedA, Mónica. Mandibula. Barcelona: Candaya, 2018.

Ojeda, Mónica. Las voladoras. Madrid: Páginas de Espuma, 2020.

OJeda, Mónica. «Estoy haciendo un abordaje del horror familiar. Entrevista a Mónica Ojeda». Entr. Daniel Gascón. Letras Libres. 23 Dic 2020. https:/www.letraslibres.com/ espana-mexico/libros/entrevista-monica-ojeda-estoy-haciendo-un-abordaje-del-horror-familiar. Consultado el 2 Mar 2021.

Pacheco, José Emilio. El principio del placer. México: Joaquín Mortiz, I972.

Pezzé, Andrea. «El sistema literario de Mónica Ojeda». Orillas, 9, (2020): 45-63. http:// orillas.cab.unipd.it/orillas/wp-content/uploads/2020/07/2020_03Pezze_rumbos.pdf. Consultado el 2 Mar 2021.

Pico Salguero, Nora Amaranta. Voladoras. La red invisible del relato. Quito: Universidad Andina Simón Bolívar, Corporación Editora Nacional, 2013. http://hdl.handle. net/10644/4019. Consultado el 2 Mar 2021.

Punter, David. The Literature of Terror. A History of Gothic Fictions From 1765 to the Present Day. London: Longman, 1980.

Quirarte, Vicente, Esquinca, Bernardo. Ciudad Fantasma. Relatos fantasmas de la Ciudad de México (Siglo XX-XXI). México: Almadía, 2013.

Ríos Acuña, Sirley. «Un acercamiento al mundo del Human Tac Eac en los Andes». Revista de Artesanía de América, 66, (2008): 103-124. http://documentacion.cidap.gob.ec:8080/ handle/cidap/1524. Consultado el 2 Mar 2021.

Roas, David. «La amenaza de lo real». David Roas (ed.). Teorías de lo fantástico. Madrid: Arco/Libros, 2001: 7-44.

RoAs, David. «El monstruo fantástico posmoderno: entre la anomalía y la domesticación». Revista de Literatura LXXXI:161, (2019): 29-56. http://revistadeliteratura.revistas.csic. es/index.php/revistadeliteratura/article/view/482. Consultado el 2 Mar 2021. https:// doi.org/10.3989/revliteratura.2019.01.002

Roas, David. «Fantástico femenino vs. Fantástico feminista. Género y transgresión de lo real». David Roas, Alessandra Massoni (eds.). Las creadoras ante lo fantástico. Visiones desde la narrativa, el cine y el cómic. Madrid: Visor, 2020: 15-30.

Rodríguez PAppe, Solange. La primera vez que vi un fantasma. Barcelona: Candaya, 20 i 8. Rojas Mrx, Miguel. América Imaginaria. Barcelona: Lumen, 1992. 
SANChis Amat, Victor Manuel. "El cuerpo habitado y la exploración de la identidad. Figuraciones de la narrativa de lo inusual en La primera vez que vi un fantasma, de Solange Rodríguez Pappe». Brumal, 8:1, (2020): 157-177. https://revistes.uab.cat/ brumal/article/view/v8-n1-sanchis/pdf-es-42. Consultado el 2 Mar 2021. https://doi. org/10.5565/rev/brumal.650

Weinstock, Jeffrey Andrew (ed.) The Monster Theory Reader. Minneapolis: University of Minnesota Press, 2020.

Zavala Medina, Daniel, Sardiñas, José Miguel. «La antología de relatos Ciudad Fantasma: del México prehispánico al caos de la modernidad». Alambique. Revista de ciencia ficción y fantasia, 7:2, (2020): 1-21. https://scholarcommons.usf.edu/alambique/vol7/iss2/1/. Consultado el 2 Mar 2021. https://dx.doi.org/10.5038/2167-6577.7.2.1 